\title{
Current themes, theoretical issues, and preoccupations in the study of sexual differentiation and gender-related behaviors
}

\author{
JANE STEWART \\ Concordia University, Montreal, Quebec, Canada
}

The field of sexual differentiation and gender-related behavior has become, over the last 30 years, one of the most vigorous areas of study in developmental psychobiology. Besides having intrinsic interest for most of us, the field provides an ideal context in which to explore the complex interrelations between genes and hormones; hormones and neurochemistry; neuron survival, growth and connectivity in different chemical and sensory environments; and the development and expression of behavior patterns as a function of hormonal and species-typical physical and social environments.

This issue of Psychobiology was not intended to provide a comprehensive review of the major areas of research in the field. A number of recent publications serve this function admirably (see, for example, Adler, Pfaff, \& Goy, 1985; Crews, 1987, reviewed this issue; Reinisch, Rosenblum, \& Sanders, 1987, reviewed this issue; Yahr, 1988). Rather, the papers published here serve as examples of ongoing research, representing the varied concerns of scientists within the field. While reading these papers and others recently published, I have been impressed by the recurrence of several themes and theoretical issues that have emerged in recent years from changing perspectives in the broader discipline of developmental biology.

Changing perspectives often have the capacity to make new findings possible, but more importantly, interpretable, and suddenly obvious. One is reminded, for example, of the better understanding of the significance of the many reports of brain hemispheric asymmetries in numerous vertebrate species (see Glick, 1985; Kolb, Sutherland, Nonneman, \& Whishaw, 1982; Nordeen \& Yahr, 1982) that came with the recognition that many parts of the body, including the brain, show maturational asymmetries in growth (Corballis \& Morgan, 1978). The realization that cell death is a normal process in the development of the nervous system and that survival depends on the chemical environment, on afferent and efferent connections, and on neuronal activity not only has transformed thinking

The preparation of this paper was supported by a grant from the Natural Sciences and Engineering Research Council of Canada. I thank Barbara Woodside for her critical reading of the manuscript. Correspondence may be addressed to Jane Stewart, Center for Studies in Behavioral Neurobiology, Department of Psychology, Concordia University, 1455 de Maisonneuve Blvd., Montreal, Quebec H3G 1M8, Canada. about the ways in which gonadal hormones and speciestypical environments might alter structure and connectivity within the brains of genetic males and females, but has, in addition, led to numerous specific discoveries of such events (see Kelley, 1988, and Toran-Allerand, 1986, for fuller discussions of these issues).

I have selected four themes from the current literature on sexual differentiation and gender-related behaviors to discuss briefly. Two of these, organizational actions of gonadal hormones beyond the perinatal period, and sensory and hormonal interactions in development, arise out of recent advances in developmental neural and behavioral biology. The latter two seem to arise from the excitement surrounding the discovery of the importance of the organization actions of gonadal hormones in sexual differentiation of brain and behavior. The importance of context as a determinant of sex differences in behavior and the need to study sexual differentiation in diverse and atypical species are themes that serve to caution against the all-too-easy assumption that sex differences in behavior and sexual differentiation itself are determined solely by the organizational actions of gonadal hormones. It will become obvious that these ideas and issues already have had impact on thinking in the field and will, no doubt, continue to influence the course of research over the next few years.

\section{Actions of Gonadal Steroids on Neural Growth and Connectivity Are Not Limited to the \\ Perinatal Period}

In 1959, Phoenix, Goy, Gerall, and Young published a paper of enormous importance and influence entitled "Organizing Action of Perinatally Administered Testosterone Propionate on the Tissues Mediating Mating Behavior in the Female Guinea Pig," in which they made an analogy between the role of testosterone on the development of the genital tract and that of testosterone on the tissues mediating mating behavior. They warned, however, that unlike embryologists who had found changes in the structure of the genitals as a result of early exposure to testosterone,

neurologists and psychologists interested in the effects of the androgen on neural tissues would hardly think of alterations so drastic. Instead, a more subtle change reflected in function rather than visible structure would be presumed.... 
We are assuming that testosterone or some of its metabolites act on those central nervous system tissues in which patterns of sexual behavior are organized. We are not prepared to suggest whether the site of action is general or localized. (p. 381)

Thus, at first it was believed that anatomical differences, if they were to be found, would be subtle, and, in fact, the first observations of sex differences in subcortical nuclei of mammalian brain were (see Dörner \& Staudt, 1968, 1969; Pfaff, 1966). These were followed by the discovery of the startling (at the time) sexual dimorphisms in the neuropil of the preoptic area and hypothalamus (Dyer, MacLeod, \& Ellendorff, 1976; Greenough, Carter, Steerman, \& DeVoogd, 1977; Matsumoto \& Arai, 1976; Raisman \& Field, 1973). In 1978, Gorski, Gordon, Shryne, and Southam reported the even more unexpected finding of a sex difference in the gross morphology of the medial preoptic area of the rat. All of these differences subsequently were found to depend on exposure to testosterone or to its estrogen metabolite during the perinatal period. These findings were accompanied by the dramatic studies of Toran-Allerand (1976), showing an influence of testosterone and estradiol on the outgrowth of neurites in fetal explants taken from brain areas with high concentrations of estrogen receptors. The discoveries of the 1970s have been followed by a flood of new ones, not only in the anatomical development of subcortical and spinal structures (for recent reviews see Rand \& Breedlove, 1988; Yahr, 1988), but also in the development of areas of cortex and hippocampus (see Diamond, 1984; Juraska, 1986; Juraska, Kopcik, Washburne, \& Perry, 1988; Stewart \& Kolb, 1988). The tentativeness with which Phoenix et al. (1959) spoke of the possible organizational actions of gonadal steroids on the developing nervous system has been swept away by the rapid developments in neurobiology.

In recent years, the idea that organizational-type actions of steroids can extend into puberty and adulthood has begun to be taken seriously. Early evidence for such a possibility did not fit easily into the prevailing view that significant plastic changes do not take place in the central nervous system beyond the perinatal period. The change in perspective that now allows us to make sense of this evidence arises in part from the finding that certain late developing structures of the brain, such as the cerebral cortex and hippocampus, remain plastic well into adulthood (see Greenough, 1986, for a recent review). Parts of these structures appear to undergo morphological changes not only as a result of experience and learning, but also, as mentioned above, as a result of exposure to gonadal hormones. Furthermore, from the study of the actions of gonadal hormones on subcortical structures, there is increasing evidence that these too can remain plastic. The neurons of the arcuate nucleus of the hypothalamus of female rats, for example, undergo marked changes at puberty in response to estrogens (Matsumoto \& Arai, 1977, 1981; Rodrigues-Sierra \& Clough, 1987); in canaries, neurons in the song system of adult females show morphological changes in response to gonadal hormones
(DeVoogd \& Nottebohm, 1981), as do those in the spinal nucleus of the bulbocavernosus (SNB) in the rat (Breedlove \& Arnold, 1981; see also Rand \& Breedlove, 1988). For recent reviews of this issue, see Arnold and Breedlove (1985), DeVoogd (1987), and Williams (1986).

Another set of findings that supports the view that plasticity in the central nervous system extends beyond the perinatal period comes from the study of recovery from damage within the system, when it is seen that neurons sprout and take up vacated synaptic space. These findings, at first viewed with skepticism, have gradually revolutionized thinking in neurobiology. Interestingly, it has been found that within some areas of the central nervous system, there are sex differences in the degree to which neurons respond in these circumstances. Loy and Milner (1980) reported a sexual dimorphism in the extent of axonal ingrowth of noradrenergic neurons to the dentate gyrus following cuts to the septal-hippocampal pathway in rats. Females exhibited much greater sprouting than did males. This greater plasticity in the hippocampal region was reversed by neonatal exposure to testosterone (Milner \& Loy, 1982). Another example of a differential effect of lesions in males and females, comes from an early study by Nance, Shryne, and Gorski (1975). They observed that in adult female rats, septal lesions greatly enhanced the effectiveness of priming injections of estradiol and progesterone on the display of female sexual behavior. In male rats, which are normally insensitive to such injections, septal lesions did not enhance sensitivity unless the animals were treated chronically with estradiol during the period immediately following surgery. Chronic injections in the absence of a lesion had no effect. Thus, it appeared that in male rats the lesion provided the conditions for estradiol to act to increase subsequent sensitivity to estradiol. This observation was followed up by Stewart and Atkinson (1977) in a study in prepubertal male and female rats. They speculated that the pubertal rise in estrogens in female rats might have contributed to the adult sex difference in response to septal lesions. If this were the case, females given septal lesions before the pubertal rise in estrogens might respond as males had done to chronic treatment with estradiol immediately following surgery. This was confirmed in tests for female sexual behavior given 3 weeks after surgery. It was found that, although females were more sensitive to estradiol in all conditions, they too showed increased sensitivity when lesions had been followed by chronic estrogen treatment. These findings gain new significance in view of the recent report by Miyakawa and Arai (1987) of anatomical changes in the lateral septum of normal adult female, but not male, rats in response to a 4-week period of treatment with estradiol.

How are we to think about these sex-related variations in plasticity in response to gonadal hormones beyond the perinatal period? One possible answer to this question may come from the generally accepted view that, in the normally developing brain, later structural plasticity is limited by the extent of earlier growth and development. Perhaps then, variations in plasticity in response to gonadal hor- 
mones in specific systems of the brains of juvenile and adult male and female animals will depend upon the extent to which brain development of a particular region is affected by organizational actions of gonadal hormones in previous periods. Similarly, following brain damage, it may be that elements that have been less affected by earlier organizational actions of gonadal hormones will be more plastic. If this were the case, then by studying the locations and concentrations of steroid receptors and aromatizing enzymes (Canick et al., 1986; MacLusky, Naftolin, \& Goldman-Rakic, 1986; MacLusky, Philip, Hurlburt, \& Naftolin, 1985; Stumpf \& Grant, 1975; Tobet, Baum, Tang, Shim, \& Canick, 1985), it should be possible to predict areas of differential plasticity in male and female brains on the basis of the perinatal hormonal environments of specific neuron groups and their target areas.

\section{Interaction Between Sensory and Hormonal Events in the Development of Sexually Differentiated Behavior Patterns}

It has long been recognized by those concerned with social development in vertebrates that animals are born with the sensory capacities to respond to certain features of their social environments. The selection of the precise stimuli to which they respond is determined largely by the circumstances of their birth, that is, by the presence of the mother, the sights, sounds, and odors of the nest. One of the great discoveries in the field of social development has been that experience with species-typical stimuli is necessary for species recognition and attachment. If, prior to exposure to such stimuli, other arbitrary stimuli are substituted, they will be responded to and will, through exposure and interaction, become preferred. There does seem to be, therefore, a period of relative plasticity in postnatal life during which stimuli in the immediate environment, because they are responded to, alter developing neural circuitry and thereby effect long-lasting changes in their significance for the animal. Fillion and Blass (1986) reported, for example, that male rats reared with mothers whose ventral surfaces were painted with a strong lemon scent mated and ejaculated readily when paired at 100 days of age with estrous females bearing the lemon odor, but mated much less readily with normally scented females. These changes in the developing neural circuitry brought about by exposure to sensory stimuli can be compared to changes produced by the organizational actions of gonadal hormones.

It becomes interesting to ask, therefore, whether differential exposure of male and female offspring to gonadal hormones in this period of neural plasticity (what Greenough, 1986, has termed the period of "experienceexpectant" plasticity) might differentially affect the influence of the social-sensory stimuli in ways that alter the later significance of stimuli in their environments? This question was addressed recently in a paper by Beyer and Feder (1987), in which they reviewed the evidence for sensory influences in neural development and considered possible mechanisms through which gonadal hormones could alter, both directly and indirectly, the influence of afferent input to hormonally sensitive structures. They argued on the basis of electrophysiological and pharmacological studies, that the excitability of neurons is altered by the presence of gonadal hormones during critical periods of neuronal development.

An example of what appears to be an indirect effect of gonadal hormones on neuronal development has been provided by Moore and her colleagues (e.g., Moore \& Morelli, 1979; see also Richmond \& Sachs, 1984), who have shown that rat mothers, in the course of licking and handling of their newborn pups, spend more time licking the anogenital region of male than of female pups. The higher levels of licking of males is brought about by a preference for the odor of their urine. The urine odor is affected by the presence of testosterone in the male. Female neonates injected with testosterone are licked and handled as much as males. The higher levels of anogenital stimulation of the infant male contributes to the pacing of adult copulatory behavior. Male rats reared with anosmic mothers that had engaged in less anogenital licking of their pups took longer to ejaculate and required more intromissions to ejaculation than did males reared with normal mothers. When injected with testosterone and tested for male sexual behavior as adults, female rat pups artificially stimulated between Days 2-14 of life had shorter interintromission intervals than did untreated females. These results suggest that features of the neonate, in this case determined by gonadal hormones, alter the sensory stimulation it experiences (see Moore, 1984, 1985, 1986).

Differential behavior towards male and female infants by their mothers has been observed in several monkey species. Mothers have been noted to take an intense interest in the genitals of newborn males and also to be more rejecting and antagonistic toward male infants. These differences in maternal behavior appear to be related to sex differences in the physical appearance and behavior of the young. It has been noted that, in interactions with their mothers, male rhesus monkeys and male chimpanzees are more aggressive than are females; they also initiate more play-fighting with their mothers. Prepubescent male rats mount and play-fight with their mothers and their peers more frequently than do females. The higher frequency of play-fighting in male rats is dependent on exposure to androgens in the perinatal period, as it is in monkeys. The sex difference in the frequency of rough-and-tumble play in rhesus monkeys reared with their mother in either isosexual peer groups or in heterosexual peer groups was little affected by rearing conditions, whereas sexual responses were (Goldfoot, Wallen, Neff, McBrair, \& Goy, 1984). A similar finding has been reported recently for the occurrence of play-solicitation in prepubescent rats (Thor \& Holloway, 1986). Another feature of these sex differences in play is that, unlike the components of copulatory behavior, play frequency is not influenced by the levels of circulating gonadal hormones present at the time of test (Joslyn, 1973; Meaney \& Stewart, 1983). Thus, the frequency of play-fighting may 
be one of the stable and important behavioral differences between prepubescent males and females in these and other species that is influenced by the organizational actions of perinatal hormones and that, in turn, affects the social environment of the developing animal (see Meaney, Stewart, \& Beatty, 1985).

Viewed in this way, organizational actions of hormones on the central nervous system taking place during periods of neuronal differentiation and growth can be thought of as predisposing individuals to respond to certain stimuli, both environmental and hormonal, in particular ways, in different situations, and at different times throughout life. A task for the future will be to specify in greater detail how experience might selectively modify the development of structure in males and females, and how structure might mediate experience in the developing organism.

\section{Context as a Determinant of Sex Differences in Behavior}

The excitement surrounding the discovery that the probability, frequency, and vigor of many sex-related behavior patterns, as well as differences in brain anatomy and physiology, could be manipulated by exposure to gonadal hormones in the perinatal period has led sometimes to the impression that such behavior differences are determined solely by early exposure to hormones. Much research has been concerned with determining where in the brain hormones exert their organizational and activational effects. When it is found that affected brain regions are ones known to be involved in the mediation of a sexually dimorphic behavior pattern, there is a tendency to act as if the relation between hormone, brain, and behavior has been explained. What tends to be forgotten in these circumstances is that behaviors occur in contexts, under particular eliciting conditions; their probability of occurrence, frequency, timing, and vigor depend on the interaction between contextual and elicting stimuli and prevailing organismic conditions (see, for example, the discussion of the social control of the occurrence of copulation in lower ranking male stumptail macaques by Nieuwenhuijsen, Slob, \& van der Werff ten Bosch, 1988). In an interesting series of studies, Goldfoot et al. (1984) have found that among male and female rhesus monkeys the occurrence of heterotypical behaviors is greatly increased in animals observed in isosexual groups. The proportion of females showing the foot-clasp mount was much higher in isosexual groups than in heterosexual groups, and, among males, the frequency of presenting in isosexual groups was as high as that among females. It would seem that if sex differences in such behavior patterns, usually considered to be sex-typical in frequency, if not in proportion of animals displaying them, are determined by the social context, it is to be expected that more subtle differences in response tendencies will be even more contextdependent. The occurrence of behavior differences between males and females has long been recognized to depend on the age at which subjects are tested, or on the presence of specific circulating hormones; less consideration has been given to the idea that the social context may determine whether or to what extent a difference in behavior is manifested. For recent discussions of the role of context in determining sex differences in behavior, see Goldfoot and Neff (1987), Goy (1987), and Lovejoy and Wallen (1988).

The importance of these observations extends beyond that of cautioning us of the need to vary and specify our conditions of testing for sex differences in behavior. Their major significance is that they focus attention on a consideration of what it is that is different between the sexes. If, for example, it can be shown that the probability of a particular behavior pattern that occurs in a particular social context can be manipulated by perinatal exposure to hormones, the interesting question then becomes, Through what mechanisms is the response to that particular stimulus context being altered? In some cases, it might be that the perinatal hormonal manipulation acts directly to make the animal more or less sensitive to the facilitating or disrupting effects of a particular class of stimuli. In another case, the hormones might act indirectly to affect an animal's early social experiences, which, in turn, might determine the way it responds to the social contextual cues. These are the issues of development discussed in the foregoing section. The evidence for contextdependent sex differences in behavior raises the problem of accounting for how concurrent sensory and organismic information is processed and integrated to determine the expression of behavior at that time. This is a problem common to the study of behavior, and one that cannot be ignored by those concerned with sex differences in behavior; it involves an understanding of sensory processing, conditioning and learning, species-typical developmental and social behavior patterns, and an understanding of the neuroanatomical and biochemical pathways underlying them.

\section{Learning from an Evolutionary Approach}

Much of the research on the hormonal mechanisms underlying sexual differentiation of central nervous system and behavior has been carried out in rodent species; major and significant exceptions are those studies of the brains of songbirds (see, for example, Nottebohm, 1980) and of the behavior of monkeys (see, for example, Goy, 1978). In the early period of the study of sexual differentiation in mammals, understanding of the relative contributions of genes, gonadal hormones, and rearing environment to sexual differentiation was illuminated by such rare genetic conditions in humans as androgen insensitivity syndrome (testicular feminization), adrenogenital syndrome, and by cases of inadvertent masculination of genetic females by drugs used therapeutically in prenatal life (for a review, see Money \& Ehrhardt, 1972). The paper by MacLusky et al. (1988) demonstrates how a rare genetic condition of androgen insensitivity found in rodents can contribute to knowledge about the relative roles of androgens and estrogens in sexual differentiation of brain and behavior (see also Beach \& Buehler, 1977; Olsen, 1979). Recently, the attention of those who have worked primarily with these few species has been drawn 
to the contributions of biologists who, viewing genderrelated differences in behavior within an evolutionary framework, have used the study of a wide variety of species, some with exceptional properties, to unravel the contribution of genes, hormones, and environmental factors to the determination of sexually differentiated behavior patterns and to explore the variety of mechanisms that have evolved for the determination of sexual reproductive behavior patterns (see, for example, Baum, Gallager, Martin, \& Damassa, 1982; Crews, 1987; Fadem \& Tesoriero, 1986; Nieuwenhuijsen et al., 1988). The paper by Adkins-Regan (1988) elegantly shows how a comparative approach has begun to contribute to an understanding of factors involved in the development of sexual orientation, a problem that has long puzzled researchers in the field (see Ellis \& Ames, 1987).

In view of the paper by Crews (1988), it suffices for me to say here that comparative studies continue to enrich our understanding of potential mechanisms involved in sexual differentiation. Studies revealing a role for such environmental factors as temperature and group structure (see, for example, Mrosovsky \& Yntema, 1980; Shapiro, 1979) and those that recently have reopened the question of a direct role for genes in the determination of sex differences (see, for example, Wai-Sum, Short, Renfree, \& Shaw, 1988) have taken advantage of some unique aspect of the species studied. These new sets of findings have served to vindicate those who have warned that the principles underlying sexually differentiated behavior (Whalen, 1986), not to mention behavior more generally (Beach, 1950), cannot be derived from the study of a few common laboratory species.

\section{REFERENCES}

ADKINS-Regan, E. (1988). Sex hormones and sexual orientation in animals. Psychobiology, 16, 335-347.

Adler, N., Pfaff, D., \& GoY, R. W. (Eds.) (1985). Handbook of behavioral neurobiology: Vol. 7. Reproduction. New York: Plenum Press.

ARNold, A. P., \& Breedlove, S. M. (1985). Organizational and activational effects of sex steroids on brain and behavior: A reanalysis. Hormones \& Behavior, 19, 469-498.

Baum, M. J., Gallager, C. A., Martin, J. T., \& Damassa, D. A. (1982). Effects of testosterone, dihydrotestosterone, or estradiol administered neonatally on sexual behavior of female ferrets. Endocrinology, 111, 773-780.

BeACH, F. A. (1950). The Snark was a Boojum. American Psychologist, 5, 115-124.

BeACH, F. A., \& Buehler, M. G. (1977). Male rats with inherited insensitivity to androgen show reduced sexual behavior. Endocrinology, 100, 197-200.

Beyer, C., \& Feder, H. (1987). Sex steroids and afferent input: Their roles in brain sexual differentiation. Annual Review of Physiology, 49, 349-364.

Breedlove, M., \& ARNold, A. (1981). Sexually dimorphic motor nucleus in rat spinal cord: Response to adult hormone manipulation, absence in androgen insensitive rats. Brain Research, 225, 297-307.

Canick, J. A., Vaccaro, D. E., Livingston, E. M., Leeman, S. E., RYAN, K. J., \& FoX, T. O. (1986). Localization of aromatise and $5 \alpha$-reductase to neuronal and non-neuronal cells in the fetal rat hypothalamus. Brain Research, 372, 277-282.

Corballis, M. C., \& Morgan, M. J. (1978). On the biological basis of human laterality: I. Evidence for a maturational left-right gradient Behavioral \& Brain Sciences, 1, 261-269.

Crews, D. (Ed.) (1987). Psychobiology of reproductive behavior: An evolutionary perspective. Englewood Cliffs, NJ: Prentice Hall.

Crews, D. (1988). The problem with gender. Psychobiology, 16, 321-334.

DEVoOGD, T. J. (1987). Androgens can affect the morphology of mammalian CNS neurons in adulthood. Trends in Neurosciences, 10 , 341-342.

DEVoogd, T. J., \& NotTebohm, F. (1981). Gonadal hormones induce dendritic growth in the adult avian brain. Science, 214, 202-204.

Diamond, M. C. (1984). Age, sex, and environmental influences. In N. Geschwind \& A. Galaburda (Eds.), Cerebral dominance: The biological foundations (pp. 134-146). Cambridge, MA: Harvard University Press.

Dörner, G., \& STAudT, J. (1968). Structural changes in the preoptic anterior hypothalamic area of the male rat, following neonatal castration and androgen substitution. Neuroendocrinology, 3, 136-140.

Dörner, G., \& STAUdT, J. (1969). Structural changes in the hypothalamic ventromedial nucleus of the male rat, following neonatal castration and androgen treatment. Neuroendocrinology, 4, 278-281.

Dyer, R. G., Macleod, N. R., \& Ellendorff, F. (1976). Electrophysiological evidence for sexual dimorphism and synaptic convergence in the preoptic and anterior hypothalamic areas of the rat. Proceedings of the Royal Society of London, 193, 421-440.

ELLIS, L., AMES, M. A. (1987). Neurohormonal functioning and sexual orientation: A theory of homosexuality-heterosexuality. Psychological Bulletin, 101, 233-258.

FADEM, B. H., \& TESORIERo, J. V. (1986). Inhibition of testicular development and feminization of the male genitalia by neonatal estrogen treatment in a marsupial. Biology of Reproduction, 34, 771-776.

FILLION, T. J., \& BLASs, E. M. (1986). Infantile experience with suckling odors determines adult sexual behavior in male rats. Science, 231 , $729-731$.

GuICK, S. D. (Ed.) (1985). Cerebral lateralization in nonhuman species. Orlando, FL: Academic Press.

GolDFOOT, D. A., \& NEFF, D. A. (1987). Assessment of behavioral sex differences in social contexts: Perspectives from primatology. In J. M. Reinisch, L. A. Rosenblum, \& S. A. Sanders (Eds.), Masculinity/femininity: Basic perspectives (pp. 179-195). New York: Oxford University Press.

Goldfoot, D. A., Wallen, K., NefF, D. A., McBriar, M. C., \& Goy, R. W. (1984). Social influences on the display of sexually dimorphic behavior in thesus monkeys: Isosexual rearing. Archives of Sexual Behavior, 13, 395-412.

Gorski, R. A., Gordon, J. H., Shryne, J. E., \& Southam, A. M. (1978). Evidence for morphological sex difference within the medial preoptic area of the rat brain. Brain Research, 148, 333-346.

GoY, R. W. (1978). Development of play and mounting in female rhesus virilized prenatally with esters of testosterone or dihydrotestosterone. In D. J. Chivers \& J. Herbert (Eds.), Recent advances in primatology: Vol. 1. Behaviour (pp. 449-462). London: Academic Press.

Goy, R. W. (1987). Assessment of behavioral sex differences: A commentary. In J. M. Reinisch, L. A. Rosenblum, \& S. A. Sanders (Eds.), Masculinity/Femininity: Basic perspectives (pp. 196-201). New York: Oxford University Press.

Greenough, W. T. (1986). What's special about development? Thoughts on the bases of experience-dependent synaptic plasticity. In W. T. Greenough \& J. M. Juraska (Eds.), Developmental neuropsychobiology (pp. 387-407). Orlando, FL: Academic Press.

Greenough, W. T., Carter, C. S., Steerman, C., \& DeVoogd, T. J. (1977). Sex differences in dendritic patterns in hamster preoptic area. Brain Research, 126, 63-72.

JosLyN, W. D. (1973). Androgen-induced social dominance in infant female rhesus monkeys. Journal of Child Psychology \& Psychiatry, 14, 137-145.

JURASKA, J. M. (1986). Sex differences in developmental plasticity of behavior and the brain. In W. T. Greenough \& J. M. Juraska (Eds.), Developmental neuropsychobiology (pp. 409-422). Orlando, FL: Academic Press. 
Juraska, J. M., Kopcik, J. R., Washburne, D. L., \& Perry, D. L. (1988). Neonatal castration of male rats affects the dentritic response to differential environments on granule neurons of the hippocampal dentate gyrus. Psychobiology, 16, 406-410.

Kelley, D. B. (1988). Sexually dimorphic behaviors. Annual Review of Neuroscience, 11, 225-251.

Kolb, B., Sutherland, R. J., Nonneman, A. J., \& Whishaw, I. Q. (1982). Asymmetry in the cerebral hemispheres of the rat, mouse, rabbit and cat: The right hemisphere is larger. Experimental Neurology, 78, 348-359.

LovejoY, J., \& W ALleN, K. (1988). Sexually dimorphic behavior in group-housed rhesus monkeys (Macaca mulatta) at 1 year of age. Psychobiology, 16, 348-356.

Loy, R., Milner, T. A. (1980). Sexual dimorphism in extent of axonal sprouting in rat hippocampus. Science, 208, 1282-1284.

Maclusky, N. J., Luine, V. N., Gerlach, J. L., Fischette, C., NAFTOLIN, F., \& McEWEN, B. S. (1988). The role of androgen receptors in sexual differentiation of the brain: Effects of the testicular feminization (Tfm) gene on androgen metabolism, binding, and action in the mouse. Psychobiology, 16, 381-397.

Maclusky, N. J., Naftolin, F., \& Goldman-Rakic, P. (1986). Estrogen formation and binding in the cerebral cortex of the developing rhesus monkey. Proceedings of the National Academy of Sciences USA, 83, 513-516.

Maclusky, N. J., Philip, A., Hurlburt, C., \& Naftolin, F. (1985). Estrogen formation in the developing rat brain: Sex differences in aromatase activity during early post-natal life. Psychoneuroendocrinology, 10, 355-361.

Matsumoto, A., \& ARAi, Y. (1976). Effect of estrogen on early postnatal development of synaptic formation in the hypothalamic arcuate nucleus of female rats. Neuroscience Letters, 2, 79-82.

Matsumoto, A., \& ARai, Y. (1977). Synaptogenic effect of estrogen on the hypothalamic arcuate nucleus of the adult female rat. Cell Tissue Research, 198, 427-433.

Matsumoto, A., \& Arai, Y. (1981). Neuronal plasticity in the deafferented hypothalamic arcuate nucleus of adult female rats and its enhancement by treatment with estrogen. Journal of Comparative Neurology, 197, 197-205.

Meaney, M. J., \& Stewart, J. (1983). The influence of exogenous testosterone and corticosterone on the social behavior of prepubertal male rats. Bulletin of the Psychonomic Society, 21, 232-234.

Meaney, M. J., Stewart, J., \& Beatty, W. W. (1985). Sex differences in social play: The socialization of sex roles. In J. S. Rosenblatt, C. Beer, M. C. Busnel, \& P. J. B. Slater (Eds.), Advances in the study of behavior: Vol. 15 (pp. 1-58). New York: Academic Press.

MILNER, T. A., \& LOY, R. (1982). Hormonal regulation of axonal sprouting in the hippocampus. Brain Research, 243, 180-185.

MiYakawa, M., \& ARAI, Y. (1987). Synaptic plasticity to estrogen in the lateral septum of the adult male and female rats. Brain Research, 436, 184-188.

MONEY, J., \& EHRHARDT, A. A. (1972). Man and woman, boy and girl: The differentiation and dimorphism of gender identity from conception to maturity. Baltimore: Johns Hopkins Press.

Moore, C. L. (1984). Maternal contributions to the development of mascine sexual behavior in laboratory rats. Developmental Psychobiology, 17, 347-356.

MoOre, C. L. (1985). Development of mammalian sexual behavior. In E. S. Gollin (Ed.), The comparative development of adaptive skills: Evolutionary implications (pp. 19-56). Hillsdale, NJ: Erlbaum.

MoORE, C. L. (1986). Interaction of species-typical environmental and hormonal factors in sexual differentiation of behavior. Annals of the New York Academy of Sciences, 474, $108-119$.

Moore, C. L., \& Morelli, G. A. (1979). Mother rats interact differently with male and female offspring. Journal of Comparative \& Physiological Psychology, 93, 677-684.

MrosovsKy, N., \& YNTEMA, C. L. (1980). Temperature dependence of sexual differentiation in sea turtles: Implications for conservation practices. Biological Conservation, 18, 271-280.

Nance, D. M., Shryne, J., \& Gorski, R. A. (1975). Facilitation of female sexual behavior in male rats by septal lesions: An interaction with estrogen. Hormones \& Behavior, 6, 289-300.
Nieuwenhuijsen, K., Slob, A. K., \& VAN der Werff ten Bosch, J. J. (1988). Gender-related behaviors in group-living stumptail macaques, Psychobiology, 16, 357-371.

Notтевонм, F. (1980). Brain pathways for vocal learning in birds: A review of the first 10 years. Progress in Psychobiology \& Physiological Psychology, 9, 85-125.

NordeEn, E. J., \& YAHR, P. (1982). Hemispheric asymmetries in the behavioral and hormonal effects of sexually differentiating mammalian brain. Science, 218, 391-394.

OLSEN, K. (1979). Androgen-insensitive rats are defeminized by their testes. Nature, 279, 238-239.

PFAFF, D. W. (1966). Morphological changes in the brains of adult male rats after neonatal castration. Journal of Endocrinology, 36, 415-416.

Phoenix, C. H., Goy, R. W., Gerall, A. A., \& Young, C. W. (1959). Organizing action of prenatally administered testosterone propionate on the tissues mediating mating behavior in the female guinea pig. Endocrinology, 65, 369-382.

Raisman, G., \& Field, P. M. (1973). Sexual dimorphism in the neuropil of the preoptic area of the rat and its dependence on neonatal androgen. Brain Research, 54, 1-29.

Rand, M. N., \& Breedlove, S. M. (1988). Progress report on a hormonally sensitive neuromuscular system. Psychobiology, 16, 398-405.

ReinisCh, J. M., Rosenblum, L. A., \& LANDERS, S. A. (Eds.) (1987) Masculinity/femininity: Basic perspectives. New York: Oxford University Press.

Richmond, G., \& SACHS, B. D. (1984). Maternal discrimination of pup sex in rats. Developmental Psychobiology, 17, 87-89.

Rodrigues-Sierra, J. F., \& Clough, R. W. (1987). Sexual dimorphism in the synaptogenic effect of estradiol in prepubertal female rats. Synapse, 1, 258-264.

SHAPIRO, D. Y. (1979). Social behavior, group structure, and the control of sex reversal in hermaphroditic fish. In J. S. Rosenblatt, C. Beer, M. C. Busnel, \& P. J. B. Slater (Eds.), Advances in the study of behavior: Vol. 10 (pp. 43-102). New York: Academic Press.

Stewart, J., \& ATKINSON, S. (1977). Effects of septal lesions on the lordotic behavior of weanling male and female rats. Hormones \& Behavior, 9, 99-106.

STEWART, J., \& KOLB, B. (1988). The effects of neonatal gonadectomy and prenatal stress on cortical thickness and asymmetry in rats. Behavioral \& Neural Biology, 49, 344-360.

StumpF, W. E., \& GRaNT, L. D. (Eds.) (1975). Anatomical endocrinology. Basel, Switzerland: Karger.

Thor, D. H., \& Holloway, W. R., JR. (1986). Social play soliciting by male and female juvenile rats: Effects of neonatal androgenization and sex of cagemates. Behavioral Neuroscience, 100, 275-279.

Tobet, S. A., Baum, M. J., TANG, H. B., Shim, J. H., \& Canick, J. A. (1985). Aromatase activity in the perinatal rat brain: Effects of age, sex and intrauterine position. Developmental Brain Research, 23, 171-178.

Toran-Allerand, C. D. (1976). Sex steroids and the development of the newborn mouse hypothalamus and preoptic area in vitro: Impli cations for sexual differentiation. Brain Research, 106, 407-412.

Toran-Allerand, C. D. (1986). Sexual differentiaton of the brain. In W. T. Greenough \& J. M. Juraska (Eds.), Developmental neu ropsychobiology (pp. 175-211). Orlando, FL: Academic Press.

Wai-Sum, O., Short, R. V., Renfree, M. B., \& Shaw, G. (1988). Primary genetic control of somatic sexual differentiation in a mammal. Nature, 331, 716-717.

WHALEN, R. E. (1986). Hormonal control of behavior: A cautionary note. Annals of the New York Academy of Sciences, 474, 354-361.

WiLliams, C. L. (1986). A reevaluation of the concept of separable periods of organizational and activational actions of estrogens in de velopment of brain and behavior. Annals of the New York Academy of Sciences, 474, 282-292.

YAHR, P. (1988). Sexual differentiation of the brain in the context of developmental psychobiology. In E. M. Blass (Ed.), Handbook of behavioral neurobiology: Vol. 9. Developmental psychobiology and behavioral ecology (pp. 197-243). New York: Plenum Press.

(Manuscript received September 20, 1988.) 